\title{
Enhanced Recovery after Elective Colorectal Surgery - Reasons for Non-Compliance with the Protocol
}

\author{
Didier Roulin ${ }^{a}$ Mirza Muradbegovic ${ }^{a}$ Valérie Addor ${ }^{a}$ Catherine Blanc ${ }^{b}$ \\ Nicolas Demartines ${ }^{a}$ Martin Hübner ${ }^{a}$ \\ ${ }^{a}$ Department of Visceral Surgery, and b Department of Anesthesiology, University Hospital of Lausanne (CHUV), \\ Lausanne, Switzerland
}

\section{Key Words}

Enhanced recovery $\cdot$ Colorectal surgery $\cdot$ Compliance

\begin{abstract}
Background/Aims: Enhanced recovery after surgery (ERAS) protocols for elective colorectal surgery reduce the intensity of postoperative complications, hospital stays and costs. Improvements in clinical outcome are directly proportional to the adherence to the recommended pathway (compliance). The aim of the present study was to analyze reasons for the non-compliance of colorectal surgeries with the ERAS protocol. Methods: A consecutive cohort of patients undergoing elective colorectal surgery was prospectively analyzed with regards to the surgery's compliance with the ERAS protocol. The reason for every single protocol deviation was documented and the decision was categorized based on whether it was medically justified or not. Results: During the 8-month study period, 76 patients were included. The overall compliance with 22 ERAS items was $76 \%$ (96\% in the preoperative, $82 \%$ in the perioperative, and $63 \%$ in the postoperative period). The decision to deviate from the clinical pathway was mainly a medical decision, while patients and nurses were responsible in 26 and $14 \%$ of the cases, respectively. However, reasons for non-compliance were medically justified in $78 \%$ of the study participants. Conclusion: 'Non-compliance' with the ERAS protocol was observed mostly in the
\end{abstract}

\section{KARGER}

E-Mail karger@karger.com

www.karger.com/dsu postoperative period. Most deviations from the pathway were decided by doctors and in a majority of cases it appeared that they were due to a medical necessity rather than non-compliance. However, almost a quarter of deviations that were absolutely required are still amenable to improvement.

(c) 2016 S. Karger AG, Basel

\section{Introduction}

Enhanced recovery after surgery (ERAS) is a multimodal evidence-based approach that optimizes the perioperative management of patients [1-3]. Those pathways are considered standard of care in colorectal surgery, as they have been shown to successfully improve postoperative recovery and reduce complications, length of stay in hospital $[4,5]$ as well as overall costs [6]. Clinical outcomes are closely associated with compliance to the ERAS pathway [7], as increasing ERAS compliance was correlated with fewer complications and shorter primary hospital stay [8]. Sustainability of ERAS pathways is dependent on the continuous monitoring of compliance with the proto-

Presented at the 100th Annual Congress of the Swiss Surgical Society, June 13, 2013, Bern, Switzerland. 
col [9]. This study detects and corrects deviations from evidence-based protocols, which might be deleterious to the patients. It is thus important not only to report application of the protocol (yes/no) but also to identify problem areas and analyze the underlying reasons.

Therefore, the aim of our present study was to analyze within an established ERAS protocol as to (i) who decided on deviations from the standardized pathway and (ii) whether those decisions were medically justified or not.

\section{Methods}

Since the implementation of a standardized ERAS protocol for all elective colorectal surgery procedures at Lausanne University Hospital in 2011 [6], demographic and surgical information along with information on perioperative care items and clinical outcome were systematically entered into a prospective database $\left(\right.$ EIAS $\left.^{\circledR}\right)$. A dedicated ERAS nurse was in charge of data management. While compliance for every individual care item was meticulously recorded, reasons responsible for deviations were not routinely documented.

The present study prospectively analyzed non-compliances of consecutive patients undergoing elective colorectal surgical procedures within an established colorectal ERAS pathway at our institution during an 8-month period from August 24, 2012 until March 25, 2013. Elective colorectal surgery comprised of any colorectal resection as well as stoma procedures performed during a planned hospital admission.

The Institutional Review Board approved the study and all patients provided written consent before surgery. The study was conducted in accordance with the STROBE criteria (http://strobestatement.org/) and registered under www.researchregistry.com (UIN: 771).

\section{ERAS Pathway}

The ERAS Society guidelines recommendations for colorectal surgery constitute the ground of our institutional ERAS protocol (table 1) and the updated versions were published recently for colorectal surgery $[2,3]$.

\section{Outcome Measures}

Compliance or non-compliance with the standardized ERAS protocol was individually assessed for each surgical procedure for each patient. Overall compliance as well as compliance in the preoperative, perioperative and postoperative periods was also reported. In case of non-compliance, the decision to deviate from the clinical pathway was made by one of the following people: surgeon, anesthetist, nurse or patient. This assessment was based on the reported decisions transcribed in the patient's medical and nurse boards. The respective protocol deviations were discussed with those concerned and classified on the basis of whether they were medically justified or not. Any controversy was resolved by the institutional ERAS core group (V.A., M.H., and C.B.).

\section{Statistical Analysis}

The compliance was obtained as the number of items successfully applied divided by the 22 items. The compliance for each item was calculated as the number of compliant patients divided by the total number of patients. Descriptive statistics for categorical variables were reported as number and percentage, while continuous variables were reported as median and interquartile range or means and SD as appropriate. Data analysis was performed using GraphPad Prism 5.0 (GraphPad Software, La Jolla, USA).

\section{Results}

\section{Patients}

Within an 8-month period, 76 consecutive patients undergoing elective colorectal surgery were included in the present prospective audit. Demographic and surgical details of this consecutive cohort are displayed in table 2.

\section{Compliance to the ERAS Protocol}

The overall compliance of elective patients to the ERAS protocol was 76\%. Preoperative measures were applied with a compliance of $96 \%$, while intraoperative and postoperative measures were followed with 82 and 63\%, respectively. Compliance with individual care items is shown in figure 1 . The overall quantum of missing information was $1 \%$.

\section{Who Was Responsible for Non-Compliance?}

The doctors (surgeons $21 \%$ and anesthetists 34\%) were chiefly responsible for non-compliance. In $26 \%$ of deviations, patients refused to follow recommendations, while in $14 \%$, nurses accounted for the deviations. In $6 \%$ of deviations combined decision-making was observed, while in $5 \%$, those who were mainly responsible for non-compliance could not be clearly identified. Those responsible for non-compliance are displayed for each individual item in figure 2.

\section{True Non-Compliance or Medical Necessity?}

Overall, deviations from the ERAS protocol were evaluated as medically justified in $78 \%$ of cases. For the remaining $22 \%$, no good clinical reason could be identified upon careful assessment of the charts and discussion with the caretakers; those deviations were therefore considered true non-compliance. Typical examples for wellfounded modifications of the intraoperative care pathway included the use of epidural analgesia, the no-routine use of abdominal drains and the use of postoperative nausea and vomiting (PONV) prophylaxis. Problematic items were the avoidance of long-term sedative, the use of postoperative analgesia and the timing to stop the epidural analgesia (fig. 3). 
Table 1. Items of the institutional ERAS protocol for elective colorectal surgery

\begin{tabular}{|c|c|}
\hline Education & Patient's preadmission counseling + written information \\
\hline Bowel preparation & Avoidance of bowel preparation \\
\hline Carbohydrate drinks & $800 \mathrm{ml}$ on evening, and $400 \mathrm{ml} 2 \mathrm{~h}$ before surgery \\
\hline Sedative & No preoperative long-acting sedative premedication \\
\hline Thrombo-prophylaxis & LMW heparin $12 \mathrm{~h}$ before surgery, IPC \\
\hline Antibiotic prophylaxis & Cefuroxime $1.5 \mathrm{~g}+$ metronidazole $500 \mathrm{mg} 30 \mathrm{~min}$ before incision \\
\hline Epidural analgesia & Thoracic epidural analgesia for laparotomy. Epidural or PCA for laparoscopy \\
\hline PONV prophylaxis & Droperidol $1 \mathrm{mg}$ at induction, ondansetron $4 \mathrm{mg} \pm$ bethametasone $4 \mathrm{mg}$ at the end of operation for Apfel score $>2$ \\
\hline Warming & Hypothermia prevention with active warming (air blanket) \\
\hline Nasogastric tubes & No routine postoperative nasogastric tube \\
\hline Abdominal drains & No routine abdominal drain \\
\hline Systematic laxatives & Oral magnesium hydroxyde \\
\hline Postoperative analgesia & Epidural or PCA. Paracetamol, ibuprofen, and oxycodone-naloxone only for breakthrough pain \\
\hline Nutrition & Normal diet at will from the day of surgery \\
\hline Postoperative fluids & Cristalloids $500 \mathrm{ml}$ during the first $24 \mathrm{~h}$ than stop \\
\hline Oral fluids & Free fluid $4 \mathrm{~h}$ after surgery \\
\hline $\begin{array}{l}\text { Mobilization at all } \\
\text { on day of surgery }\end{array}$ & $\begin{array}{l}\text { Rising from bed } 4 \text { times more than } 30 \text { min (to walk, or to sit in chair counts as mobilising, but not sitting on the } \\
\text { edge of bed) }\end{array}$ \\
\hline Bladder catheter & Removal on POD 1 \\
\hline Energy POD 1 & 2 oral nutritional supplements ( $300 \mathrm{kcal} / \mathrm{unit}$ ) per day \\
\hline Mobilization at 1 st POD & At least $6 \mathrm{~h}$ per day \\
\hline Stop epidural analgesia & Removal of thoracic epidural analgesia or PCA at POD 2 \\
\hline 30 days follow up & Postoperative control after 30 days \\
\hline
\end{tabular}

Table 2. Demographics and surgical characteristics of patients undergoing elective colorectal surgery

\begin{tabular}{|c|c|}
\hline Characteristics & $\mathrm{n}=76$ \\
\hline Age, years* & $59(18)$ \\
\hline Sex ratio, $\mathrm{M}: \mathrm{F}$ & $41: 35$ \\
\hline \multicolumn{2}{|l|}{ ASA grade, $n$} \\
\hline I-II & 62 \\
\hline III-IV & 14 \\
\hline \multicolumn{2}{|l|}{ Diagnosis, $\mathrm{n}$} \\
\hline Neoplasia & 53 \\
\hline Diverticular disease & 18 \\
\hline Inflammatory disease & 5 \\
\hline \multicolumn{2}{|l|}{ Surgical approach, $\mathrm{n}$} \\
\hline Laparoscopic & 34 \\
\hline Open & 38 \\
\hline Converted & 4 \\
\hline \multicolumn{2}{|c|}{$\begin{array}{l}\text { * Values calculated as mean (SD). } \\
\text { ASA }=\text { American Society of Anesthesiologists. }\end{array}$} \\
\hline 222 & \\
\hline
\end{tabular}

\section{Discussion}

The present analysis shows that the evaluation of compliance with the ERAS protocol is of importance and emphasizes 2 aspects: the majority of deviations from an ideal protocol are observed during the postoperative course and deviations are mostly based on well-founded medical decisions. In contrast, $22 \%$ of true non-compliances were not justified and clearly showed that despite an established ERAS protocol there is further room for improvement in perioperative care.

The monitoring of compliance with regard to the ERAS protocol is essential in order to improve clinical outcome [8]. Comparing our present study with other studies could be difficult because of the difference in the items as well as due to the difference in the number of items, which ranged from 4 to 14 in a systematic review

Roulin/Muradbegovic/Addor/Blanc/ Demartines/Hübner 
Fig. 1. ERAS protocol compliance. $A B=$ Antibiotic; $\mathrm{NG}=$ nasogastric $; \mathrm{POD}=$ postoperative day; $\mathrm{FU}=$ follow up.

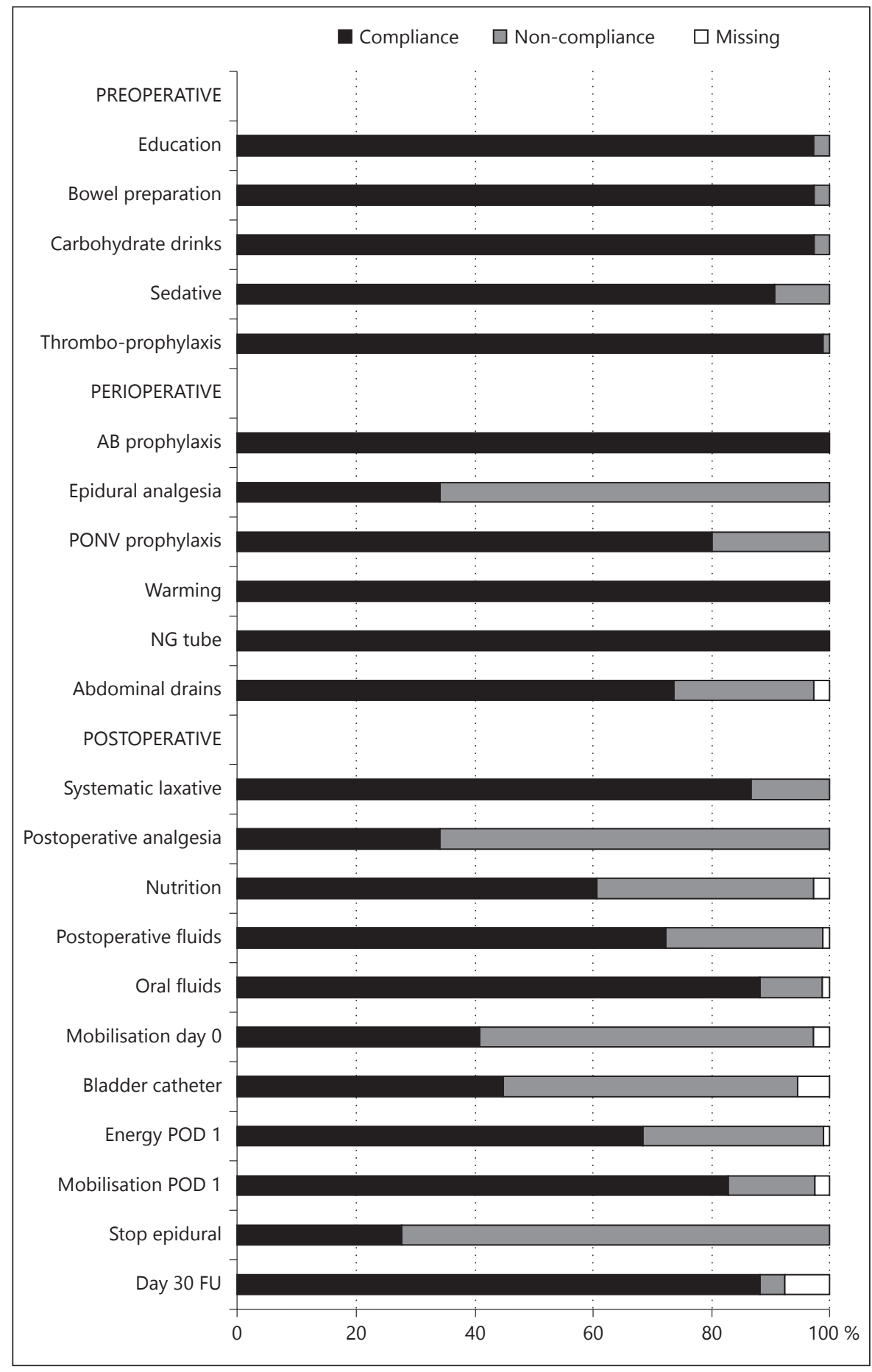

complications on compliance to postoperative items [8], postoperative items were also reported and analyzed.

Some problematic items in the perioperative and postoperative phases were observed and deserve further discussion. The item 'epidural analgesia' with a compliance

Dig Surg 2017;34:220-226
Reasons for Non-Compliance in Enhanced Recovery Protocol 
Fig. 2. Responsible of non-compliance. For abbreviations refer fig. 1 legend.

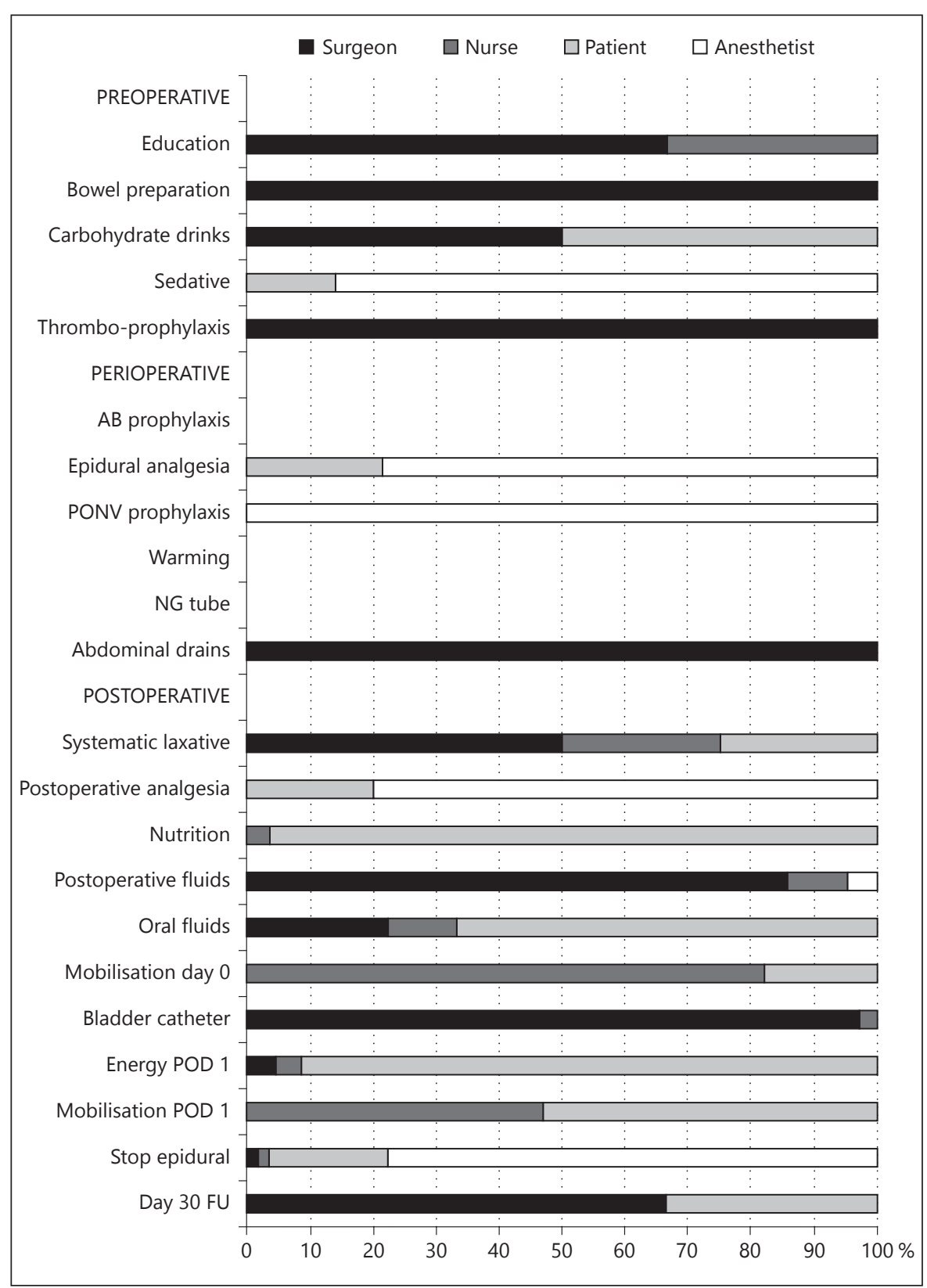

of about $34 \%$ was artificially low in our study compared to other studies because of an ongoing controlled randomized trial comparing epidural versus patient-controlled analgesia for laparoscopic colorectal surgery [12]. In line with ERAS recommendations and previous data [13], we follow a no-routine-drain policy in our department. However, low rectal resections or heavily contaminated surgical fields constitute accepted indications for surgical drains for a limited duration [3]. The results of the GRECCAR V trial (NCT01269567) are eagerly await- ed and based on these results, the ERAS guidelines is expected to be revised accordingly. A high level of noncompliance for PONV prophylaxis could be explained by the fact that the protocol for PONV prophylaxis was adapted during the time of the present study. At the beginning of study, the ERAS guidelines were strictly followed, based on the use of Apfel score [14] for the calculation of PONV risk with the administration of PONV prophylaxis for Apfel score higher than 2. After the first half of the study period, up to $35 \%$ of PONV were ob-
Roulin/Muradbegovic/Addor/Blanc/ Demartines/Hübner 
Fig. 3. Justification of non-compliance. For abbreviations refer fig. 1 legend.

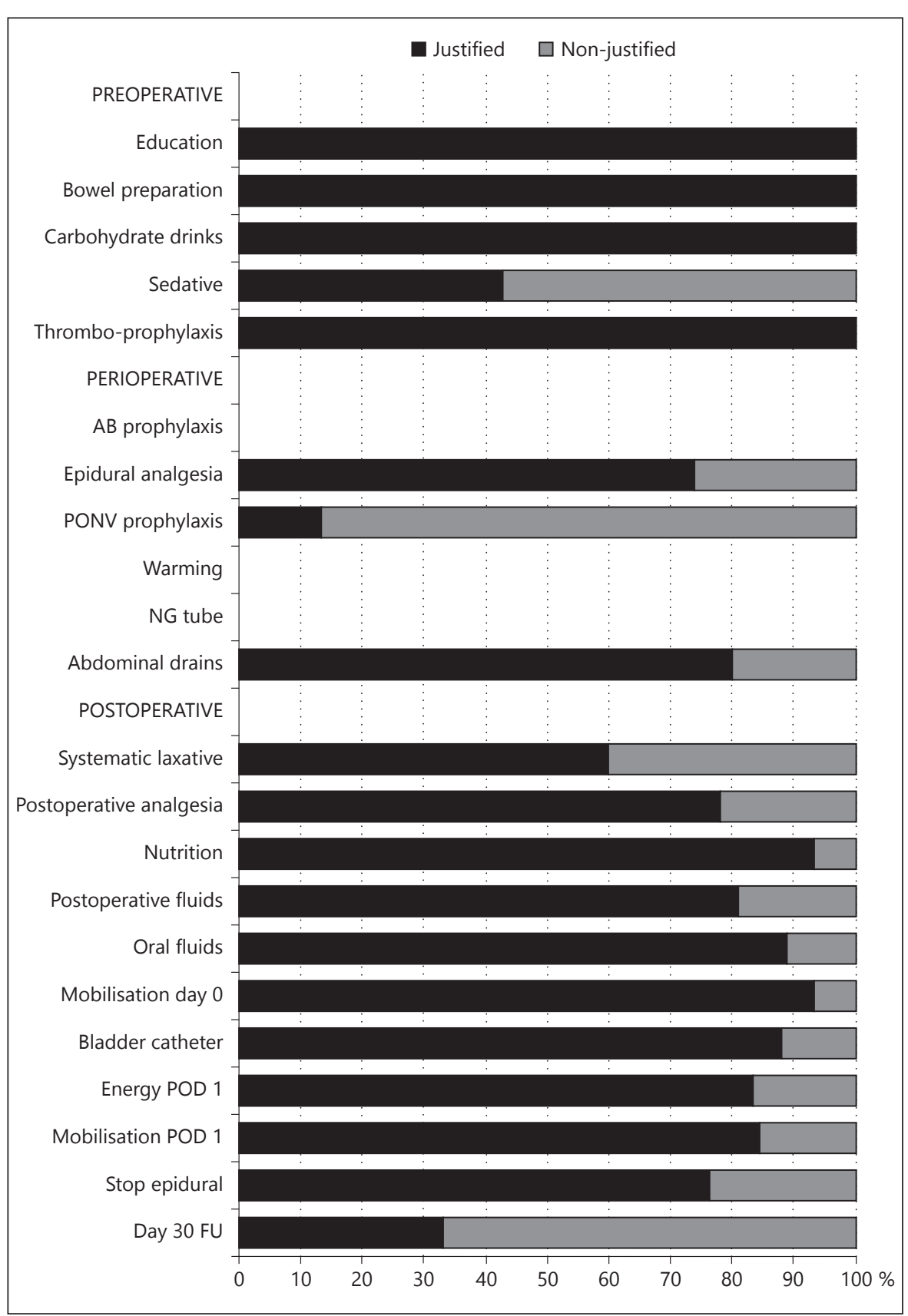

served. This was discussed in the regular ERAS team meeting and it was decided that a PONV prophylaxis be given systematically to all patients with a drop of PONV to $10 \%$.

While the ERAS protocol is overall a comprehensive bundle of potentially beneficial measures, perioperative care should not be regarded as a rigid system. The physician remains in charge and needs to conform to or modify the foreseen pathway according to the individual needs and actual clinical situation of every single patient. In fact, $78 \%$ of the deviations were found to be an utterly required deviation of the pathway from a medical point of view and in the patient's best interest. So it should not be surprising that the surgeon or the anesthetist who was in charge of the surgery was mainly responsible for initiating protocol deviations. Patients were mostly non-compliant for items concerning early food intake like supplements, oral fluids and energy at first postoperative day. Another example 
was the patient's mobilization. We observed that those who were responsible for protocol deviation were both nurses and patients. This could be explained by the fact that often in the postoperative period, patients have some hypotension and may be symptomatic, thereby preventing their mobilization. A previous study that assessed how patient factors influence compliance identified male gender, age above 75 and American Society of Anesthesiologists $3 / 4$ as independent predictors for non-compliance to most postoperative items [15].

Several limitations of this study need to be addressed. The current data reflect our institutional experience and cannot be generalized to other hospitals. The study sample is rather small but still sufficient to fulfill the aims and answer the questions of this prospective analysis. Obviously, there is no objective criterion to label whether clinical decisions were medically justified or not. However, a careful joint analysis of the ERAS team appeared to be a good and reliable approach to this important subject. Despite these limitations, to the best of our knowledge, this study is the first prospective one that has assessed the reasons and causal factors for non-compliance with the ERAS protocol.
In summary, high compliance with the ERAS protocol can be achieved in all phases of perioperative care. The postoperative period, however, seems to be more subject to variation and close observation is warranted to adjust patient care if medically indicated. The compliance or adherence to ERAS protocol should be monitored and reported in every scientific study to enhanced recovery. Having said this, if the ERAS protocol does not fit a few individual patients perfectly, it still is suitable for a majority of them.

\section{Acknowledgments}

The authors would like to acknowledge the support provided by all members of the enhanced recovery team in Lausanne.

\section{Sources of Support and Funding}

None.

\section{Disclosure Statement}

The authors have no conflicts of interest to declare.

\section{References}

1 Wind J, Polle SW, Fung Kon Jin PH, Dejong $\mathrm{CH}$, von Meyenfeldt MF, Ubbink DT, Gouma DJ, Bemelman WA; Laparoscopy and/or Fast Track Multimodal Management Versus Standard Care (LAFA) Study Group; Enhanced Recovery after Surgery (ERAS) Group: Systematic review of enhanced recovery programmes in colonic surgery. Br J Surg 2006;93: 800-809.

2 Gustafsson UO, Scott MJ, Schwenk W, Demartines N, Roulin D, Francis N, McNaught CE, MacFie J, Liberman AS, Soop M, Hill A, Kennedy RH, Lobo DN, Fearon K, Ljungqvist O; Enhanced Recovery after Surgery Society: Guidelines for perioperative care in elective colonic surgery: enhanced recovery after surgery $\left(\right.$ ERAS $\left.^{\circledR}\right)$ society recommendations. Clin Nutr 2012;31:783-800.

3 Nygren J, Thacker J, Carli F, Fearon KC, Norderval S, Lobo DN, Ljungqvist O, Soop M, Ramirez J; Enhanced Recovery after Surgery Society: Guidelines for perioperative care in elective rectal/pelvic surgery: enhanced recovery after surgery $\left(\right.$ ERAS $\left.^{\circledR}\right)$ society recommendations. Clin Nutr 2012;31: 801-816.

4 Spanjersberg WR, Reurings J, Keus F, van Laarhoven CJ: Fast track surgery versus conventional recovery strategies for colorectal surgery. Cochrane Database Syst Rev 2011; 2:CD007635.
5 Greco M, Capretti G, Beretta L, Gemma M, Pecorelli N, Braga M: Enhanced recovery program in colorectal surgery: a meta-analysis of randomized controlled trials. World J Surg 2014;38:1531-1541.

6 Roulin D, Donadini A, Gander S, Griesser AC, Blanc C, Hübner M, Schäfer M, Demartines N: Cost-effectiveness of the implementation of an enhanced recovery protocol for colorectal surgery. Br J Surg 2013;100:11081114.

7 Gustafsson UO, Hausel J, Thorell A, Ljungqvist O, Soop M, Nygren J; Enhanced Recovery after Surgery Study Group: Adherence to the enhanced recovery after surgery protocol and outcomes after colorectal cancer surgery. Arch Surg 2011;146:571-577.

8 ERAS Compliance Group: The impact of enhanced recovery protocol compliance on elective colorectal cancer resection: results from an international registry. Ann Surg 2015;261:1153-1159.

9 Gillissen F, Ament SM, Maessen JM, Dejong $\mathrm{CH}$, Dirksen $\mathrm{CD}$, van der Weijden $\mathrm{T}$, von Meyenfeldt MF: Sustainability of an enhanced recovery after surgery program (ERAS) in colonic surgery. World J Surg 2015;39:526-533.

10 Ahmed J, Khan S, Lim M, Chandrasekaran TV, MacFie J: Enhanced recovery after surgery protocols - compliance and variations in practice during routine colorectal surgery. Colorectal Dis 2012;14:1045-1051.

11 Cakir H, van Stijn MF, Lopes Cardozo AM, Langenhorst BL, Schreurs WH, van der Ploeg TJ, Bemelman WA, Houdijk AP: Adherence to enhanced recovery after surgery and length of stay after colonic resection. Colorectal Dis 2013;15:1019-1025.

12 Hübner M, Blanc C, Roulin D, Winiker M, Gander S, Demartines N: Randomized clinical trial on epidural versus patient-controlled analgesia for laparoscopic colorectal surgery within an enhanced recovery pathway. Ann Surg 2015;261:648-653.

13 Petrowsky H, Demartines N, Rousson V, Clavien PA: Evidence-based value of prophylactic drainage in gastrointestinal surgery: a systematic review and meta-analyses. Ann Surg 2004;240:1074-1084; discussion 1084-1085.

14 Apfel CC, Greim CA, Haubitz I, Goepfert C, Usadel J, Sefrin P, Roewer N: A risk score to predict the probability of postoperative vomiting in adults. Acta Anaesthesiol Scand 1998; 42:495-501.

15 Feroci F, Lenzi E, Baraghini M, Garzi A, Vannucchi A, Cantafio S, Scatizzi M: Fast-track surgery in real life: how patient factors influence outcomes and compliance with an enhanced recovery clinical pathway after colorectal surgery. Surg Laparosc Endosc Percutan Tech 2013;23:259-265. 